\title{
LIDERANÇA ORGANIZACIONAL: DISCUSSÃO SOBRE UM CONCEITO-CHAVE À ADMINISTRAÇÃO
}

\author{
ORGANIZATION LEADERSHIP: DISCUSSION ABOUT A KEY CONCEPT FOR BUSINESS \\ ADMINISTRATION
}

\author{
Sérgio Alves \\ Universidade Federal de Pernambuco - UFPE
}

\section{RESUMO}

A liderança é uma concepção complexa e polissêmica que permeia várias áreas do conhecimento. A análise do processo de liderança envolve dimensões contravenientes, tais como, subjetividadeobjetividade e agente-estrutura, e quase sempre está associada à ocorrência de mudanças. Este ensaio ressalta os seus aspectos relacionados com o âmbito microssocial das organizações, ou mais precisamente, com o campo da pesquisa organizacional. 0 presente trabalho tem o propósito de contribuir para o ordenamento do debate sobre esse conceito-chave à administração. Para tanto ele discute a controversa relação indivíduo e estrutura; descreve a noção de liderança acolhida por dois autores clássicos, M. Weber e S. Freud; explicita a diferenciação entre líder e gestor, embora estes dois termos não representem uma antinomia entre si; e, finalmente, focaliza o papel da liderança nas transformações substantivas da organização.

Palavras-chave: Liderança. Líder. Gestor. Agente. Estrutura.

\begin{abstract}
Leadership is a complex concept and is a notion with varies meanings that permeates many areas of knowledge. The analysis of the leadership process involves contravenientes dimensions, such as, subjective-objective and agent-structure, and is almost always associated with change. This text, however, will highlight the aspects related to corporations and its social behavior, or more precisely, the field of organizational research. Hence, the current work discusses the controversial relationship between individuals and structure; it describes the notion of leadership chosen by two classic authors: M. Weber and S. Freud; it emphasizes the difference between leader and manager, even though these two terms do not represent opposition between each other; it focuses leadership on the substantial transformation of the corporation.
\end{abstract}

Key words: Leadership. Leader. Manager. Agent. Structure. 


\section{INTRODUÇÃO}

A importância da liderança é amiúde exaltada pela literatura especializada em administração como um fator diferencial da maior relevância para um melhor desempenho das organizações formais complexas. Contudo, observa-se uma considerável variedade quanto ao entendimento do processo de liderança e, não raro, até certa banalização conceitual sobre o que efetivamente este fenômeno significa.

A concepção mais simples e geral de liderança se refere a um ato de condução de pessoas e grupos que leva ao destaque de pelo menos quatro elementos básicos: i) o líder com suas características de habilidade e personalidade, e seus recursos para a determinação das incumbências do grupo; ii) seus seguidores, também com suas competências e capacidades; iii) as atividades a serem empreendidas pelos componentes do grupo; e iv) a situação em si e sua relação com o ambiente externo.

Posto isso, é preciso explicitar o primeiro desses elementos constitutivos: o líder. Ele é um indivíduo cujas características lhe permitem exercer influência e tomar decisões sob o reconhecimento espontâneo do grupo; é alguém cuja vontade, sentimentos, habilidades e intuição mobilizam pessoas em prol da causa que representa.

Nas ciências sociais aplicadas e, particularmente, na área de administração são encontradas várias incursões conceituais sobre essa temática (BERGAMINI, 2006; CRAINER, 2006; SPECTOR, 2005; VERGARA, 2003): i) a liderança implica a existência de uma relação particular de influência entre uma pessoa e um grupo; ii) no processo de liderança, o líder manifesta suas habilidades inatas; iii) para se compreender a liderança é recomendável estudar a personalidade e o comportamento de líderes reconhecidos e descrever os seus traços característicos e a sua forma de agir; iv) liderança é o processo de influenciar e motivar um grupo de pessoas para que contribuam para atingirem determinados objetivos; v) a liderança é algo específico de um dado contexto, o que requer diferentes maneiras do líder atuar; vi) no exercício da liderança ressalta-se um relacionamento entre o líder e o grupo, baseado na troca racional ou na oferta de recompensas simbólicas e tangíveis em função do desempenho grupal; vii) a liderança refere-se à capacidade de alguém em influenciar, motivar e gerar satisfação nos grupos para alcançarem determinados resultados etc.

Diante dessa profusão de entendimentos sobre líder e liderança, necessário se faz o resgate desse conceito-chave para a administração e, mais precisamente para a pesquisa organizacional. Isto é, procurar retornar a um ponto de partida localizado na confluência da sociologia com a psicanálise. Com efeito, a análise do processo de liderança, inspirada em perspectivas dotadas de robustez teórica, contribui para o seu melhor entendimento. Destarte, a releitura de clássicos como M. Weber e S. Freud é alentadora e profícua, pois suscita reflexões, estimula discussões e fundamenta argumentações que alcançam os escopos micro e macrossocial (organizações e sociedade). Antes, porém, serão explicitadas duas perspectivas sobre a relação indivíduoestrutura, uma vez que esta controversa questão permeia a temática da liderança.

\section{INDIVÍDUO E ESTRUTURA: ABORDAGENS UNILATERAIS}

Tendo-se por referência a concepção de estrutura e a noção de agente, a sociologia das organizações e a teoria geral da administração apresentam diversas correntes rivais. Essas abordagens contravenientes poderiam ser ilustradas, simplificadamente, posicionando-as em um continuum, onde em um dos seus extremos estaria representada a ênfase ao estrutural e 
no outro o destaque para a ação individual.

Correntes de pensamento como a positivista, a coletivista e a objetivista, supõem estarem os indivíduos enredados na armadilha de um mecanismo complexo em que as relações objetivas estruturam as suas práticas e ações. Sob essa ótica, as mudanças são ordenadas pelos padrões, regras e propriedades não redutíveis às propensões individuais ou às paixões humanas.

No início do século passado a crescente complexidade do processo de produção industrial e as exigências do mercado em expansão passaram a requerer uma maior sistematização de procedimentos, mais rotinas e regulamentações, além da presença de gestores profissionais. Com efeito, o tratado pioneiro sobre a produtividade da mão-de-obra industrial, de F. W. Taylor, contém proposições para a gestão de grandes unidades fabris. 0 taylorismo transpõe para o campo da gestão organizacional uma ética associada às primeiras etapas do desenvolvimento capitalista que correspondia a um desenho organizacional-administrativo com perfil monocrático e fundado na obediência. Ao lado dessas idéias, o fordismo consolida o sistema de produção em massa nas linhas de montagem de fábricas de automóveis, onde também se ressalta a implantação de um regime de oito horas de trabalho e a introdução da premiação financeira por produtividade.

Quase simultaneamente, surge na França o fayolismo que propõe diretrizes relacionadas com as atividades de previsão, organização, comando, fiscalização e coordenação.

Nessas abordagens o indivíduo encontra-se confinado em papeis minuciosamente definidos pelo topo da hierarquia que procura adaptá-lo às necessidades do sistema produtivo. 0 trabalhador é destituído do seu ritmo natural e o seu aparato psicossocial é condicionado pelas conveniências das tecnologias e dos equipamentos de produção.

A incapacidade desses enfoques em lidar com as incertezas e imprevisibilidades próprias das transações ambiente-organização conduziu à adoção de uma perspectiva voltada para as influências exógenas à organização, representada pelo contingencialismo. Esta escola do pensamento administrativo propiciou uma razoável acumulação de resultados de pesquisas em campo sobre como as organizações mudam e se adaptam às circunstâncias externas. Para ela não há uma estrutura organizacional única e que seja efetiva em todas as condições. Significa dizer que a configuração organizacional irá variar em conformidade com a natureza das tarefas, o tipo de estratégia, à tecnologia adotada, o porte da organização, entre outros.

Em seguida toma corpo a abordagem institucionalista que também considera o indivíduo como incapaz de promover transformações organizacionais segundo a sua vontade (SELZNICK, 1972).

Nela é aceito que o indivíduos podem ser sobre-socializado pelas organização da qual participa, fazendo com que eles venham a seguir as normas sem maiores reflexões e submetendo-se sem grande resistência aos scripts institucionalizados. Sustenta que a mudança organizacional é determinada mais de fora para dentro, e que as organizações estão inseridas em um ambiente do qual elas procuram assegurar apoio para o seu crescimento e perpetuação. E que as organizações que operam em um mesmo contexto ambiental tendem a assumir configurações isomórficas.

0 pós-modernismo na pesquisa organizacional, cuja origem está principalmente no estruturalismo francês, considera que os discursos estruturam o mundo e a subjetividade das pessoas, provendo-as de uma identidade social e de um modo particular de ser. Para os pósmodernistas, na medida em que a sociedade se torna fragmentada, as formas 
estabilizadoras das identidades são perdidas, rejeitando, por conseguinte, a noção do indivíduo autônomo e autodeterminado, como elemento central de análise.

Por sua vez, a primazia do indivíduo em relação à estrutura está refletida no idealismo, no individualismo e no subjetivismo, onde se salienta o que os agentes sentem, pensam e fazem.

Assume que as mudanças decorrem da ação e interação de indivíduos que podem alterar o curso dos acontecimentos. A resistência ao discurso organizacional, que privilegia o sistemaorganização em detrimento do indivíduo, manifesta-se mediante tensões informais internas e por pressões articuladas externamente.

Os estudos de E. Mayo sobre relações humanas no ambiente de trabalho industrial decorreram da necessidade de serem procuradas novas formas para integrar os trabalhadores às organizações, diante dos efeitos provocados pela concentração do capital, pela formação de grandes unidades fabris. Os resultados apontaram que o moral dos grupos é relevante para a produtividade e que a organização informal, a despeito da hierarquia, regras e rotinas, é um importante mecanismo identitário, especialmente quando o grupo se percebe ameaçado. 0 avanço que essas pesquisas proporcionaram, em termos do deslocamento do foco de investigação, até então predominante sobre o sistema-organização, para temas relacionados com produtividade individual e grupal, motivação, ambiente de trabalho, dinâmica de grupos, entre outros, não exime esses estudos de severa crítica a muitas de suas generalizações.

Destarte, foi observado naquele experimento que a gerência amistosa e a supervisão sem rigidez têm por efeito uma maior produtividade. Posteriormente, todavia, foi verificada uma relação inversa: uma maior produtividade faz com que os gerentes se tornem mais atenciosos e a supervisão mais flexível. A correlação entre satisfação no trabalho e produtividade também leva a conclusões ambíguas. Assim, a afirmativa de que quanto maior a satisfação no trabalho, maior é a produtividade, é contrariada por outras, como: quanto mais produtivo o empregado, mais satisfeito estará e a produtividade será elevada se for percebida pelo empregado como um meio para a realização de seus objetivos pessoais (WEICK, 1973).

Vários estudos organizacionais que se seguiram à experiência de Hawthorne sofreram uma decisiva influência das idéias emergentes do behaviorismo, segundo o qual o comportamento humano é fortalecido por suas conseqüências, sendo estas denominadas de reforço. Para esses comportamentalistas um reforço positivo fortalece o comportamento que o produza, quer dizer, os estímulos modificam a probabilidade das respostas virem a ser emitidas e a presença deles pode induzir a conduta das pessoas para determinados fins.

Reduzindo os processos organizacionais ao comportamento individual e supondo que se pode manter o controle na organização apoiando-se em ameaças de inclusão ou de retirada de recompensas reais ou percebidas, os behavioristas construíram um conjunto de proposições gerais, a exemplo das contidas na teoria das trocas, que são freqüentemente utilizadas na gestão organizacional. Esta abordagem também apresenta alguma semelhança com a teoria da escolha racional, na medida em que ambas consideram que o indivíduo avalia os custos e benefícios das diferentes alternativas, recorrendo a critérios de maximização da sua utilidade, e age de acordo com a opção que melhor atende aos seus interesses, com base nas oportunidades emergentes e nos desejos que acalenta.

Entre as correntes de pensamento que se debruçaram sobre autonomia individual e integração social está a teoria crítica, que se fundamenta em alguns pressupostos originários 
da escola de Frankfurt. 0 seu foco é a discussão sobre a natureza construída das pessoas e objetos, e na revelação da linguagem como um importante componente do mecanismo de construção de sentidos. Propugna pela difusão de um humanismo ativista, por uma lógica emancipatória que se contraponha à idéia de que o mundo é um conjunto de processos objetiváveis que se procura conhecer e controlar, e onde o agente individual pouco pode fazer para refletir sobre si mesmo.

Para se contrapor à socialização organizacional, ao carreirismo e à tecnocracia, considera crucial o enriquecimento do estoque de conhecimentos dos agentes e a democratização das tomadas de decisões.

\section{INDIVÍDUO E ESTRUTURA: INFLUÊNCIAS RECÍPROCAS}

Não ceder a extremos reducionistas e a presunções radicais sobre estruturas que enclausuram indivíduos passivos, ou sobre misteriosos dotes pessoais ou extraordinária magia do gênio individual, ajuda ao pesquisador a obter uma melhor validade explicativa sobre o fenômeno organizacional.

Para superar posições unilaterais caracterizadas pelo destaque à estrutura ou pela ênfase ao indivíduo, desenvolveram-se propostas que articulam estas duas dimensões-chave, considerando-as como mutuamente influentes.

Organizações e indivíduos podem ser tratados como dimensões analíticas estreitamente articuladas e reciprocamente atuantes, muito embora possam ocorrer situações específicas em que uma delas possa temporariamente predominar (ALVES, 2003). Os indivíduos podem desenvolver práticas que tanto criam, quanto reproduzem estruturas. E as propriedades estruturantes (regras e recursos) são dotadas de uma causalidade condicionante que não determina a ação dos indivíduos, mas a restringe ou a facilita. Em sendo assim, a integração social é obtida pela conduta reflexiva das experiências humanas, tendo em vista os propósitos dos agentes (BECK, GIDDENS e LASH, 1997).

De sua parte, para contrapor-se ao "sistema" que oprime a subjetividade dos agentes, a proposta habermasiana enfatiza a comunicação dialógica como mecanismo para compartilhar regras e torná-las reflexivas. Isto é, o indivíduo age racionalmente na medida em que se vale de uma comunicação livre e não distorcida. Mas, esse dizer algo a alguém e compreender o que é dito requer interlocutores que compartilhem a mesma fonte de verdade. Dessa maneira, em lugar do mero exercício da autoridade, da tradição ou da ideologia, utiliza-se a força dos argumentos para se chegar a um entendimento ou para se mudar o pensamento e a ação do interlocutor. Isso proporcionaria a base para a mais reflexiva forma de racionalidade - a comunicativa - onde a linguagem apresenta-se como o principal elemento de integração e de socialização. Essa visão, portanto, fundamenta-se na dialogicidade, na comunicação aberta entre pessoas autônomas e bem intencionadas que conservam a confiança dos parceiros, preservam os relacionamentos e reconhecem os outros como fins e não meios. Ela também considera que, se cada um efetivamente falar a verdade, não distorcer os significados das falas, nem coagir os interlocutores, isso também será seguido pelos demais (HABERMAS, 1987).

De sua parte, a abordagem weberiana ressalta o entendimento interpretativo da conduta social à luz da atribuição de um sentido ou em conformidade com um significado subjetivo dado pelos agentes. Conquanto ela valorize a intencionalidade da ação perpetrada por indivíduos dotados de alguma autonomia para proceder as suas escolhas, para agir segundo 
seus desejos e para se desenvolverem de acordo com suas potencialidades, Weber (1999) não se permite restringir a uma perspectiva unidimensional, nem aceita a totalidade social como apenas advindas dos seus constituintes individuais. Ele repele o determinismo histórico, mas reconhece a contínua e incerta luta para se manter a individualidade e o espírito criador humano em face da objetividade das forças históricas presentes no desenvolvimento do processo de produção capitalista e diante da burocratização que encaminha os indivíduos na direção do sufocamento da sua liberdade criativa.

Com efeito, o indivíduo possui uma razoável liberdade para decidir, com base em seus interesses e conhecimentos, sobre quais diretrizes irão orientar a sua organização, tendo em vista as finalidades estabelecidas e os meios disponíveis. A sua atuação, entretanto, sempre está sujeita a pressões, condicionamentos e restrições de origens interna e externa. Em poucas palavras, a organização faz os indivíduos que a fazem e os indivíduos fazem a organização que os faz.

Contudo, este processo não ocorre nas situações que os agentes forjaram totalmente por vontade própria, mas sim que eles encontram parcialmente como condições dadas.

De todo modo, é razoável assumir-se a proposição que se assenta em uma perspectiva multilateral e dialógica, que considera o indivíduo e a organização como aspectos fortemente interligados e mutuamente influentes, ou melhor, "o agente individual e o sistemaorganização são dimensões estreitamente articuladas e reciprocamente condicionantes" (ALVES, 2003: 58).

\section{O PROCESSO DE LIDERANÇA NA VISÃO DE DOIS CLÁSSICOS}

$\mathrm{Na}$ formação de grupos sociais capazes de subsistirem e dotados de alguma estabilidade observa-se a ocorrência de uma partenogênese, ou melhor, para que eles surjam e persistam é necessário um fenômeno deflagrador. Isto é, a constituição do grupo se dá quando um conjunto de indivíduos coloca um só e um mesmo objeto no lugar do seu ideal de ego. Esse objeto é representado principalmente por um líder, que personifica os anseios de mudança e se torna o ideal do "eu" dos membros do grupo, os quais, a partir dele, se identificam entre si. Os componentes do grupo abandonam o seu ideal de ego e o substitui pelo do grupo de que é parte, tal como é corporificado no líder. Dito de forma mais precisa, tem-se uma situação em que "iguais que se identificam uns com os outros, mas todos desejando ser dirigidos por uma só pessoa, considerada superior a todos eles" (FREUD, 1976: 154).

Essa identificação líder-seguidor, derivada da afeição, temor e admiração pelo dirigente idealizado, leva os membros do grupo a condutas consideravelmente previsíveis e padronizadas (ENRIQUEZ, 1990). O líder seria então uma referência daquilo que os seus seguidores desejam se tornar. Sob um viés psicanalítico, nessa relação o líder é "aquele que opera em virtude de sua semelhança com o pai e por cujo amor a realização é levada a cabo" (FREUD, 1975: 140). Isso faz com que os seus seguidores desenvolvam uma forte atração por ele e ajam segundo o seu desígnio, ou de acordo com a missão que encarna, ou pela causa que personifica. Com o desaparecimento da liderança os laços entre os membros do grupo se enfraquecem e o grupo tende a se dispersar. No entanto, como alguns grupos continuam mesmo sem ele, neofreudianos substituíram esse núcleo central do argumento por uma idéia ou imagem transcendente que pode substituí-lo, na suposição de que indivíduos vão à procura de um líder, assim como em busca de sua mensagem, o que pode garantir a continuidade da organização. 
Muda-se, portanto, a forma, mas não a lógica dessa dominação que pressupõe a aceitação voluntária e o compromisso espontâneo com a missão por ele articulada.

Para Weber (1999), há sempre a possibilidade de alguém convencer, seduzir e submeter à vontade de um conjunto de pessoas. Assim, o líder dotado de traços carismáticos é o núcleo de uma estrutura na qual os outros precisam dele, ao passo que ele necessita de outros enquanto coletividade. 0 aparecimento de um tempo de solidariedade extraordinária é creditado ao líder e depende do vínculo que se estabelece entre ele e seus seguidores, em torno de um mesmo propósito. Entretanto, ao contrário do criador da psicanálise, ele considera que o grupo não se dissolve com o desaparecimento do líder.

Muito embora o carisma seja um dom pessoal e conseqüentemente intransferível, sob determinadas circunstâncias, pode se proceder a sua sucessão por alguém previamente designado pelo próprio líder ou pelos seus colaboradores mais próximos e dedicados. Nesse caso ocorreria o que Weber denomina de rotinização ou objetivação do carisma. Evidente que esse substituto não irá dispor das mesmas condições para mobilizar e conduzir pessoas. De qualquer modo, é destino de uma estrutura centrada em um líder com traços carismáticos dar lugar aos poderes da tradição ou burocráticos.

0 reconhecimento do líder é um aspecto fundamental de um processo mais amplo, cuja origem está na noção de status nascendi - expressão utilizada por Weber (1999: 331) para definir a liderança com traços carismáticos, em sua fase embrionária. Os indivíduos nesse estado se reconhecem uns aos outros e constituem um grupo excepcionalmente solidário que pode ser encontrado em qualquer nível de agregação social. Não há uma antecedência obrigatória do líder em relação ao grupo.

O que faz nascer a necessidade de um líder como um pólo instaurador de um grupo social estável é a impossibilidade deste em viver longas e intensas situações de experimentação. Em tais circunstâncias são inevitáveis as tensões que podem degradar a sua integridade (ALBERONI, 1991). Essa propensão ao conflito entre seus membros ocorre principalmente nos grupos inovadores, na medida em que nestes "as comunicações criativas são permeadas de expressões de desacordos" (ENRIQUEZ, 1990: 316). De qualquer modo, uma posição central na rede de comunicações organizacionais contribui significativamente sobre uma maior probabilidade de um líder ou de um gestor orientar a conduta mais apropriada dos seguidores ou dos subordinados, em relação às finalidades estabelecidas.

Finalmente é oportuno sublinhar que tanto Freud, como Weber, convergem em um ponto crucial, embora trilhando diferentes caminhos: ambos reservam um lugar de destaque para as idéias e a personalidade na rede causal de importantes acontecimentos, ao lado de outros fatores situacionais e de caráter impessoal.

\section{O LÍDER E O GESTOR: DIFERENÇAS E SEMELHANÇAS}

0 exercício da liderança em um ambiente organizacional está inserido em um processo que requer e integra determinadas habilidades e competências do líder. Como habilidade considere-se aquelas peculiaridades inatas que o distinguem como pessoa; e como competência entenda-se as técnicas e os métodos de ação reveladas e desenvolvidas no cotidiano do trabalho. Ambas coexistem no indivíduo de maneira imbricada e somente em certas situações pode-se vislumbrar uma nítida distinção entre elas.

A predominância relativa de uma ou de outra pode ser observada na comunicação argumentativa ou no processo decisório que se fundamentem: no uso de mecanismos mentais 
intuitivos, inatos e intransferíveis, posto que originários de aptidões pessoais; ou na adoção de procedimentos lógicos, generalizáveis e delegáveis, por estarem alicerçados no aprendizado profissional.

Como se sabe, o pleno alcance dos objetivos organizacionais acolhidos pela liderança deparase sempre com restrições decorrentes da racionalidade limitada do decisor diante de problemas inéditos e complexos (SIMON, 1971), bem como com situações em que ocorrem conseqüências não-pretendidas da ação perpetrada (BOUDON, 1979). Tais circunstâncias corroem a pretensão dos decisores em obter concomitantemente uma elevada previsibilidade e uma minimização das incertezas nos seus esforços voltados para o atingimento dos resultados ou efeitos desejados no âmbito de uma organização formal complexa (MARCH e SIMON, 1967).

Assim, no processo de resolução de um problema cuja repercussão das decisões tomadas restrinja-se a aspectos predominantemente técnicos, a exemplo da operacionalização de um novo método de controle de qualidade, espera-se um desempenho mais orientado em função do seu conhecimento instrumental. No caso de conflito de natureza pessoal ou grupal, que ponha em risco o espírito de cooperação, é requerida uma ação capaz de reconstruir laços sócio-afetivos. E quando está em jogo um interesse organizacional mais complexo e de amplo alcance faz-se necessário considerar a dimensão cultural.

Tendo em vista o caráter polissêmico associado à concepção de líder, este termo é freqüentemente tratado pela chamada literatura gerencialista como um sinônimo de gestor. Mas, por outro lado, não se tem uma clara antinomia quanto aos significados desses dois termos. Por conseguinte, para se afastar dessas duas tentações simplificadoras e reducionistas é de todo conveniente estabelecer algumas diferenças e semelhanças entre um e outro.

O líder organizacional pode ser considerado como um generalista, um visionário, alguém que se distingue por possuir uma personalidade persuasiva, sedutora e capaz de provocar uma interação com seus seguidores fundada em sentimentos com um elevado teor de afetividade, e esses se identificam entre si e a partir dele, e agem em conformidade com a missão que o líder personifica. Ele possui a audácia de inovar, inspira confiança, tem uma perspectiva de longo prazo e preocupa-se mais com as interações do que com a atividade administrativa em si.

Independentemente de sua posição na estrutura hierárquica da organização ele opera sobre fatores emocionais, além dos recursos físicos, tecnológicos e financeiros, e ainda articula significados adstritos à trajetória histórico-cultural da organização, cujo desenvolvimento, em geral, teve e tem nele o seu principal protagonista (ALVES, 2003).

No que diz respeito a um gestor, o que o diferencia de um líder é que, ao contrário deste, a sua autoridade está necessariamente amparada pela hierarquia formalmente estabelecida. Em relação ao líder, ele não desperta em seus subordinados sentimentos tão intensos, nem constitui fortes vínculos sócio-afetivos, nem tampouco é um paladino de profundas transformações do status quo organizacional. Para o gestor prevalece uma visão de curtomédio prazo e a sua preocupação é primordialmente com o bom desempenho do sistema gerencial e com a conquista de metas e resultados satisfatórios. Por certo ele procura assegurar a otimização dos recursos disponíveis e o alcance dos objetivos da organização que gerencia, porém dificilmente consegue promover mobilização entusiástica e comprometimento espontâneo das pessoas, que é típico dos seguidores do líder.

Entretanto algumas atitudes semelhantes são requeridas para um e para o outro, no esforço 
de obtenção de um melhor desempenho organizacional. Ressalvadas aquelas peculiaridades associadas a cada um deles, é necessário que ambos, o líder e o gestor (DRUCKER, 2000; ROBBINS, 2006): i) delineiem as crenças e os valores organizacionais; ii) formulem as diretrizes e objetivos estratégicos; iii) selecionem as pessoas-chave para por em prática a sua filosofia de negócio; iv) estabeleçam as retribuições às pessoas pela adoção do comportamento desejado; v) criem mecanismos de controle que orientem o desempenho pretendido; vi) atuem como facilitador da execução de tarefas, assegurando meios para a realização dos objetivos; vii) orientem os integrantes do sistema técnico-operacional para alcançarem melhores padrões de qualidade; viii) esclareçam o "futuro pretendido" para a organização; ix) interpretem os cenários alternativos, procurando minimizar as ameaças e maximizar as oportunidades; $\mathrm{x}$ ) motivem os integrantes da organização para perceberem as suas atividades como autogratificante; xi) suportem a freqüente convivência com a tensão e os riscos; xii) construam redes de relacionamentos com pessoas e grupos externos; xiii) promovam a integração entre os diversos segmentos organizacionais; xiv) ajudem os integrantes da organização a compreenderem a inevitável convivência de componentes burocráticos, tradicionais e afetivos que, em momentos distintos e em diferentes intensidades, estão sempre presentes nas diversas configurações organizacionaladministrativas.

\section{CONSIDERAÇÕES FINAIS}

As transformações organizacionais amplas e profundas implicam em alterações substantivas de natureza estrutural, comportamental, estratégica e cultural. Quanto a esta última, importa dizer que tais mudanças afetam inclusive as crenças e os valores compartilhados, que foram difundidos na organização a partir das escolhas e preferências de sua liderança.

Nesse sentido, o líder organizacional é por excelência um vetor a nortear e induzir um novo comportamento desejado em relação a um propósito mais ambicioso, concomitantemente com a preservação da unidade interna e com o esforço de adaptação às circunstâncias externas (ALVES, 1997). Ele exerce um controle sócio-normativo para a consolidação de sua filosofia diretiva, a qual é condicionada pelos eventos críticos que a organização tenha vivenciado ao longo da sua histórica.

Por sua vez, o gestor ora atua para manter o status quo, ora age para obter mudanças de âmbito mais limitado e com a expectativa por resultados mais rápidos.

Para atender às demandas dos ambientes interno e externo à sua organização, o líder necessita possuir alguma competência na esfera instrumental, e uma especial sensibilidade nas dimensões social e cultural. As três coexistem e se expressam, em graus variáveis, no seu agir, sabendo-se que o saber instrumental está associado à idéia de conhecimento técnico, o social reflete a aptidão em bem se relacionar com membros do seu grupo e fora dele, e o cultural se refere ao talento em apreender a totalidade organizacional.

Oportuno também sublinhar que a (re)criação da cultura, que alicerça e indica o alinhamento das dimensões estrutural e estratégica, decorre, em última análise, da atuação da liderança em meio a um processo contínuo de organização-interações-reorganização. Em outras palavras, a (re)significação simbólica e a (re)instauração do sistema de valores compartilhados são indissociáveis do papel e das ações da liderança organizacional.

Em surgindo um novo momento excepcional, especialmente uma situação de crise ou de graves ameaças à organização, provavelmente outro ciclo de liderança poderá ser iniciado, 
configurando-se novos arranjos sócio-técnicos, recriando-se novos vínculos afetivos e modificando-se o conjunto de crenças e valores até então prevalecente.

Nessas condições, pouco freqüentes na vida de uma organização, o fenômeno da emergência de um novo líder irá decorrer de um processo que abarca as suas habilidades, a sua personalidade, os propósitos compartilhados, as interações entre os membros do grupo e entre estes e o líder.

\section{REFERÊNCIAS}

ALBERONI, F. Gênese. Rio de Janeiro: Rocco, 1991.

ALVES, S. Racionalidade, carisma e tradição nas organizações empresariais contemporâneas. Recife: EDUFPE, 2003.

Revigorando a cultura da empresa. São Paulo: Makron Books, 1997.

BECK, U; GIDDENS, A; LASH, S. Modernização reflexiva. São Paulo: Ed. UNESP, 1997.

BERGAMINI, C.W. Psicologia Aplicada á Administração. São Paulo: Atlas, 2006.

BOUDON, R. Efeitos perversos e ordem social. Rio de Janeiro: Zahar, 1979.

CRAINER, Stuart. Os grandes pensadores da Administração: as idéias que revolucionaram o mundo dos negócios. São Paulo: Futura, 2000.

DRUCKER, P. (Org.). Liderança para o século XXI. São Paulo: Futura, 2000.

ENRIQUEZ, Eugène. Da horda ao Estado: psicanálise do vínculo social. Rio de Janeiro: Zahar, 1990.

FREUD, Sigmund. Psicologia de grupo e a análise do ego. In: FREUD, Sigmund. Obras completas de Sigmund Freud. Rio de Janeiro: Imago, 1976. p. 91 - 171. v. XVIII.

. Moisés e o monoteísmo. In: FREUD, Sigmund. Obras completas de Sigmund Freud. Rio de Janeiro: Imago, 1975. p. 91 - 161. v. XXIII.

LEVINE, Donald N. Visões da tradição sociológica. Rio de Janeiro: Zahar, 1997.

MARCH, J. G.; SIMON, H. A. Teoria das organizações. Rio de Janeiro: FGV, 1967.

ROBBINS, Stephen P. Administração: Mudanças e Perspectivas. São Paulo: Saraiva, 2006.

SELZNICK, Philip. A liderança na administração: uma interpretação sociológica. Rio de Janeiro, FGV, 1972.

SIMON, Herbert A. Comportamento administrativo. Rio de Janeiro: FGV, 1971.

SPECTOR, Paul E. Psicologia nas Organizações. São Paulo: Saraiva, 2005.

VERGARA, Sylvia C. Gestão de Pessoas. 3aed. São Paulo: Atlas, 2003.

WEBER, Max. Economia e sociedade. Revisão técnica de Gabriel Cohn. Brasília: Ed. UNB, 1999. v. 2. 
WEICK, Karl. A Psicologia social da organização. São Paulo: EDUSP, 1973. 